\title{
Desenvolvimento de um Aplicativo Móvel para a Rede de Cooperação Solidária de Mato Grosso
}

\author{
Elmo Batista de Faria ${ }^{1}$, Josiel Maimone de Figueiredo ${ }^{1}$, Alessandra Maieski², \\ Irapuan Noce ${ }^{1}$, Oscar Zalla Sampaio Neto ${ }^{3}$
}

${ }^{1}$ Instituto de Computação - Universidade Federal de Mato Grosso (UFMT) - Cuiabá MT - Brasil.

${ }^{2}$ Instituto de Educação - Universidade Federal de Mato Grosso (UFMT) - Cuiabá MT - Brasil

${ }^{3}$ Faculdade de Nutrição- Universidade Federal de Mato Grosso (UFMT) - Cuiabá MT - Brasil.

$\{$ elmo,josiel, irapuan\}@ic.ufmt.br, alessandramaieskig1@hotmail.com,
oscarsampaio@ufmt.br

\begin{abstract}
The small producers belonging to the lowland cuiabana, when exercising their professional activity, act individually without a collective articulation, being dependent on middlemen who buy their products to resell. For products to be marketed directly to end customers and stakeholders, the use of a marketing application is of fundamental importance to producers. In this context, this article aims to present the development of a mobile application $(A P P)$, to facilitate the commercialization and control of production inventories.
\end{abstract}

Resumo. Os pequenos produtores, pertencentes a baixada cuiabana, quando no exercício de sua atividade profissional, atuam de forma individual, sem uma articulação coletiva, ficando na dependência de atravessadores que compram seus produtos para revender. Para que os produtos sejam comercializados diretamente aos clientes finais e interessados, a utilização de um aplicativo de comercialização é de fundamental importância para os produtores. Neste contexto, este artigo tem como objetivo principal apresentar o desenvolvimento de um aplicativo para dispositivo móvel (APP), para facilitar a comercialização e controle de estoques da produção.

\section{Discussões iniciais}

Os pequenos agricultores quando no exercício de sua atividade profissional, atuam de forma individual sem uma articulação coletiva, ficando na dependência de atravessadores que compram seus produtos, legalmente ou não, pagando baixos preços, porém, estando sempre presentes para a aquisição dos produtos. A consequência tem sido a descontinuidade de projetos, o abandono de propriedades rurais e a queda da qualidade de vida das comunidades tradicionais frente ao resto da população brasileira. Isso tem significado a perda dos métodos de manejo tradicional e a sua substituição por métodos não adaptados e por isso danosos ao ecossistema. 
Antes de adentrar no que tange ao proposto nesse artigo, é de fundamental importância fazer uma contextualização do Programa de Extensão Tecnológica "Rede de Cooperação Solidária de Mato Grosso" (RECOOPSOL) ${ }^{1}$, que atende prioritariamente empreendimento econômico solidários da região dos territórios da Cidadania da Baixada Cuiabana Rurais do Alto Paraguai e da Região Sul do Estado de Mato Grosso Em particular o território da Cidadania da Baixada Cuiabana está localizado nos ecossistemas Pantanal e Cerrado do Estado de Mato Grosso. Este Território da Cidadania abrange uma área de $85.369,70 \mathrm{Km}^{2}$, composto por 14 municípios, tendo as cidades de Cuiabá e Várzea Grande como o maior mercado consumidor do estado. A população total do Território da Cidadania da Baixada Cuiabana é de 976.064 habitantes, dos quais 77.147 vivem na área rural, o que corresponde a 7,90\% do total. Possui 10.260 agricultores familiares, 11.154 famílias assentadas, 49 comunidades quilombolas e 4 terras indígenas. O. Z. (2014).

Diante dessas características, compreende-se que o desenvolvimento do Aplicativo apresentado aqui, irá fomentar um ambiente colaborativo, promovendo arranjos produtivos locais, comercialização direta e coletiva e uma comunicação integrada entre as organizações. Através dele, será possível promover a comercialização, a integração e a divulgação dos produtos da Rede, proporcionando um maior contato dos consumidores com produtores, através de uma comunicação voltada para o consumo consciente. Nesse sentido, o objetivo desse artigo é apresentar os passos do desenvolvimento de um aplicativo de compra e venda de produtos, para facilitar a comercialização e controle de estoques da produção para os pequenos produtores.

\section{Caminhos metodológicos}

Os procedimentos metodológicos realizados na criação do APP, exigiu primeiramente uma pesquisa sobre ferramentas computacionais para o desenvolvimento de aplicativos para dispositivos móveis. Perpassando pela construção com códigos computacionais as funcionalidades do aplicativo e montando uma infraestrutura de banco de dados para armazenagem de informações de estoque dos produtos comercializados. A modelagem de software utilizada se baseou em três ferramentas de documentação.

\subsection{Modelagem de Processos BPMN (Business Process Model and Notation)}

A notação BPMN especifica o processo de negócio em um diagrama fácil de ler tanto para os usuários técnicos quanto para os usuários de negócios, é intuitiva e permite a representação de detalhes complexos do processo. A simbologia BPMN serve como uma linguagem padrão, permitindo a comunicação entre a modelagem do processo e sua execução. Dufresne and Matins (2003).

A figura 1 apresenta os processos iniciais que compõe o sistema de negociação de produtos gerados pelas comunidades e pequenos produtores rurais.

\footnotetext{
${ }^{1}$ A Universidade Federal de Mato Grosso (UFMT), juntamente com outras entidades realizam uma ação conjunta no projeto "Rede de Cooperação Solidária de Mato Grosso", participando de uma grande ação de sensibilização para causas da Economia Solidária e de ações articuladas de formação, fortalecimento dos Colegiados de Economia Solidária, assessoramento técnico e potencialização de plataformas de comercialização para geração de renda para povos e comunidades tradicionais e agricultores familiares. Este trabalho contou com o apoio do Departamento de Economia Solidária do Ministério da Cidadania (DESOL/MC).
} 


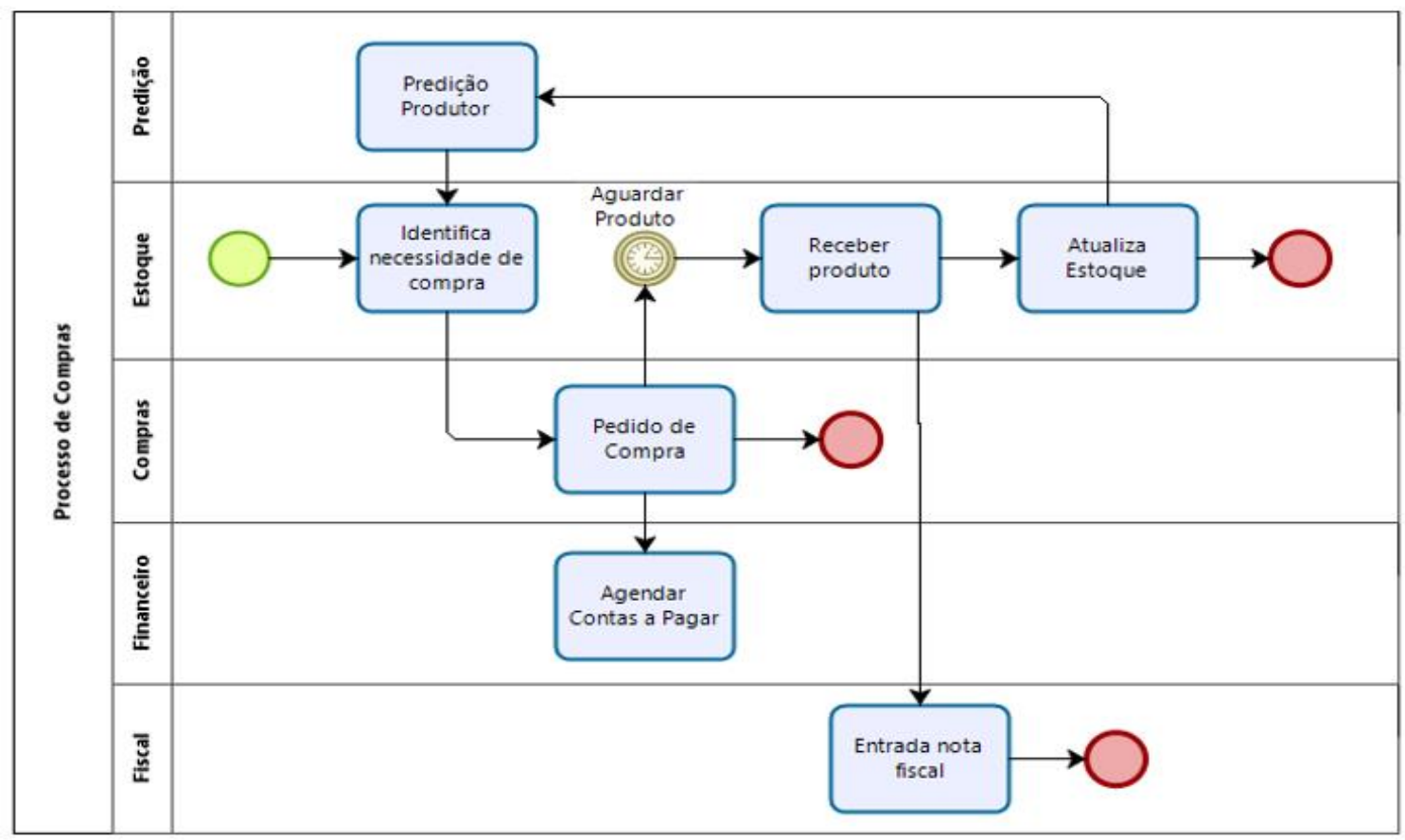

Figura 1 - Processo de compras dos sistemas confeccionado no software Bizagi.

A notação BPM indica o caminho por onde percorre todo o processo de compra e venda de mercadorias, que são compostas por produtos da agricultura familiar e de empreendimentos econômico solidários (EES), dentre eles: frutas, verduras, alimentos processados e produtos do artesanato local, oriundo das comunidades de toda baixada cuiabana.

\subsection{Prototipação de telas com uso de storyboards}

Os storyboards são utilizados na confecção de historias em quadrinho e no cinema, podem também ser utilizados na diagramação de prótotipo de telas e construir um enredo na dinâmica das telas de programas de computador. Gress (2014).

A semelhança com os quadrinhos, se faz pelo fato de o storyboard também ter uma história, sendo contada através de uma sequência de quadros e pelo fato de também se utilizar de recursos como ângulos e técnicas de composição de uma cena. No entanto, o desenho de um storyboard está mais assemelhado a uma pintura em estilo impressionista, do que os estilos marcados a nanquim, comuns nas histórias em quadrinhos. Isso se deve também ao fato de que a imagem de um storyboard precisar transmitir uma impressão mais fiel de uma imagem real, sem, no entanto, determinar muitos detalhes, que no momento em que o storyboard é feito seria de menor importância, sendo mais importante transmitir a sequência e clima de uma cena.

Em todo o mercado audiovisual, o storyboard é utilizado para um desenho animado ou para uma superprodução cinematográfica, sendo o seu recurso uma maneira relativamente, fácil, simples e barata. As telas de um software possuem todas as características de uma cena de cinema, porém descrevem como a tela vai ser apresentada ao usuário e destacam algumas de suas funcionalidades. Figura 2. 


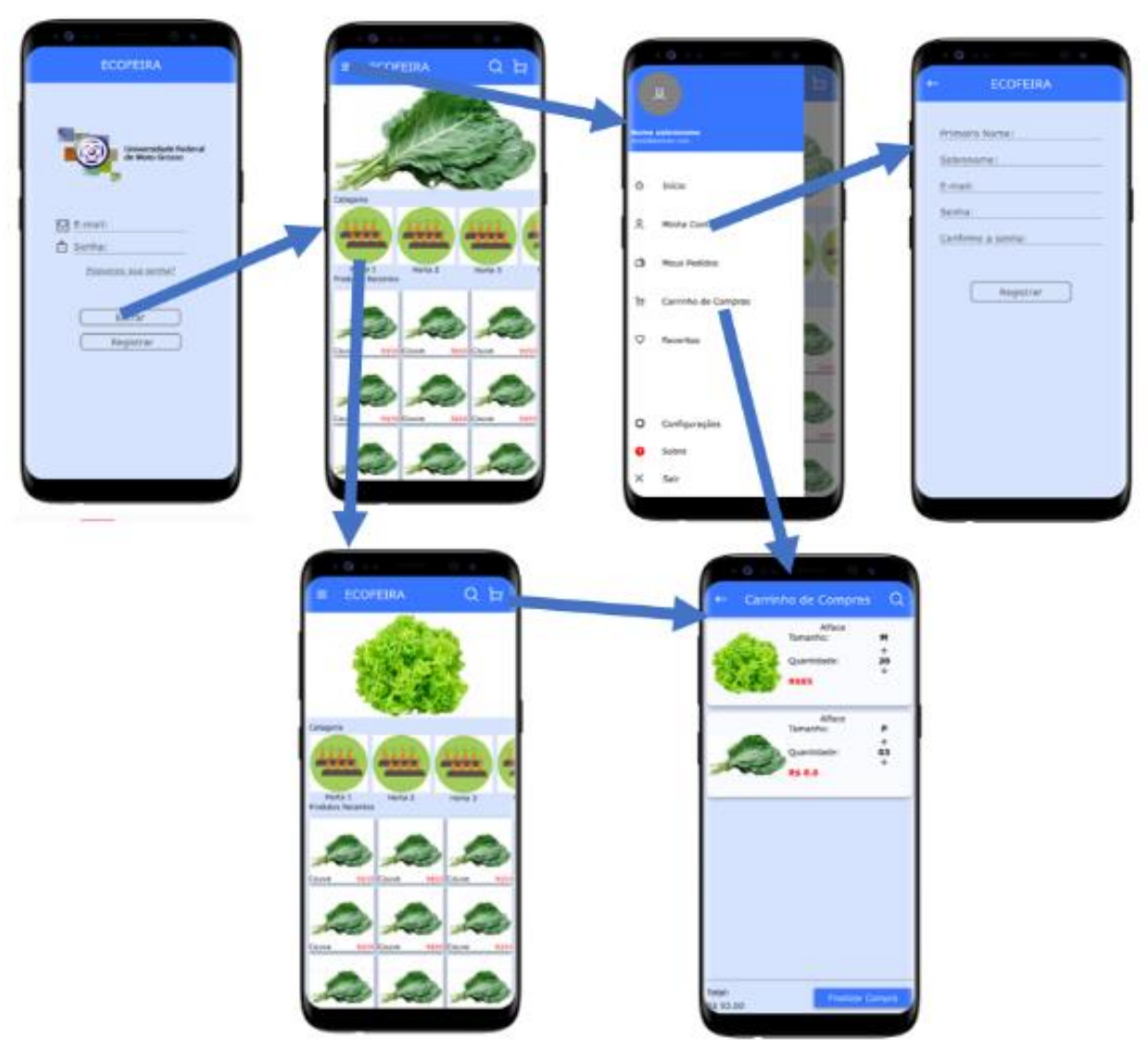

Figura2 - Storyboard das telas do APP do cliente. (Software InvisionApp)

\subsection{Base de dados}

A base de dados foi modelada no software BRModelo, ferramenta livre para modelagem de dados, um diagrama entidade relacionamento (DER), característico de um sistema de compra e venda foi desenvolvido. Para uso das aplicações foi utilizado o banco de dados Postgresql.

\section{Resultados}

Foram desenvolvidas três aplicações envolvendo todo o processo de comercialização:

- O sistema Backend, que é uma aplicação web desenvolvida no framework Django, que utiliza python como linguagem principal de desenvolvimento;

- O aplicativo para dispositivo móvel do cliente, desenvolvido na plataforma do Android Studio e utilização do framework Flutter;

- O aplicativo do produtor para dispositivo móvel, desenvolvido no Android Studio.

3.1. Sistema de retaguarda, para cadastros gerais e acompanhamento das atividades desenvolvidas em campo. 


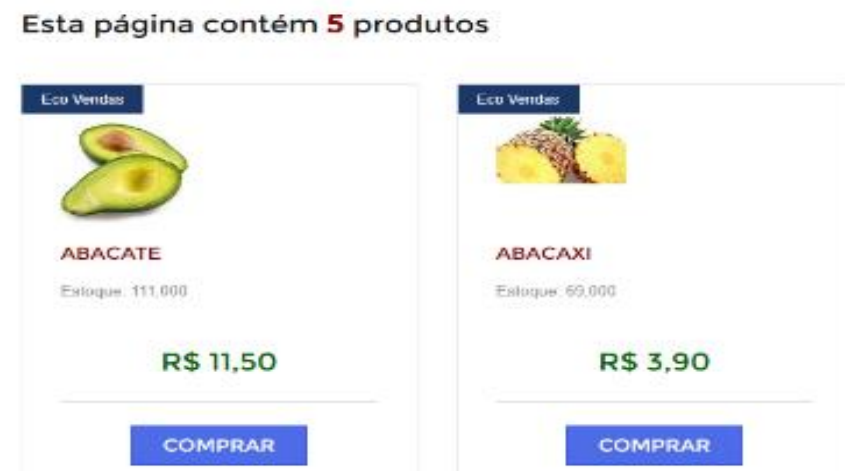

Figura 3 - Sistema web, para cadastras gerais e monitoramento de vendas.

A figura 3 apresenta o sistema web desenvolvido para cadastro e comercialização pela web, este sistema dá suporte as operações realizadas pelos aplicativos desenvolvidos. Todo o processo de cadastro básico, é realizado por este sistema, além da validação de clientes e produtores envolvidos no processo de comercialização.

\subsection{Aplicativo do Cliente}

O aplicativo do cliente e do produtor são apresentados na figura 4, suas funcionalidades básicas de compra e processo de retirada de produtos em pontos de entrega em Cuiabá.
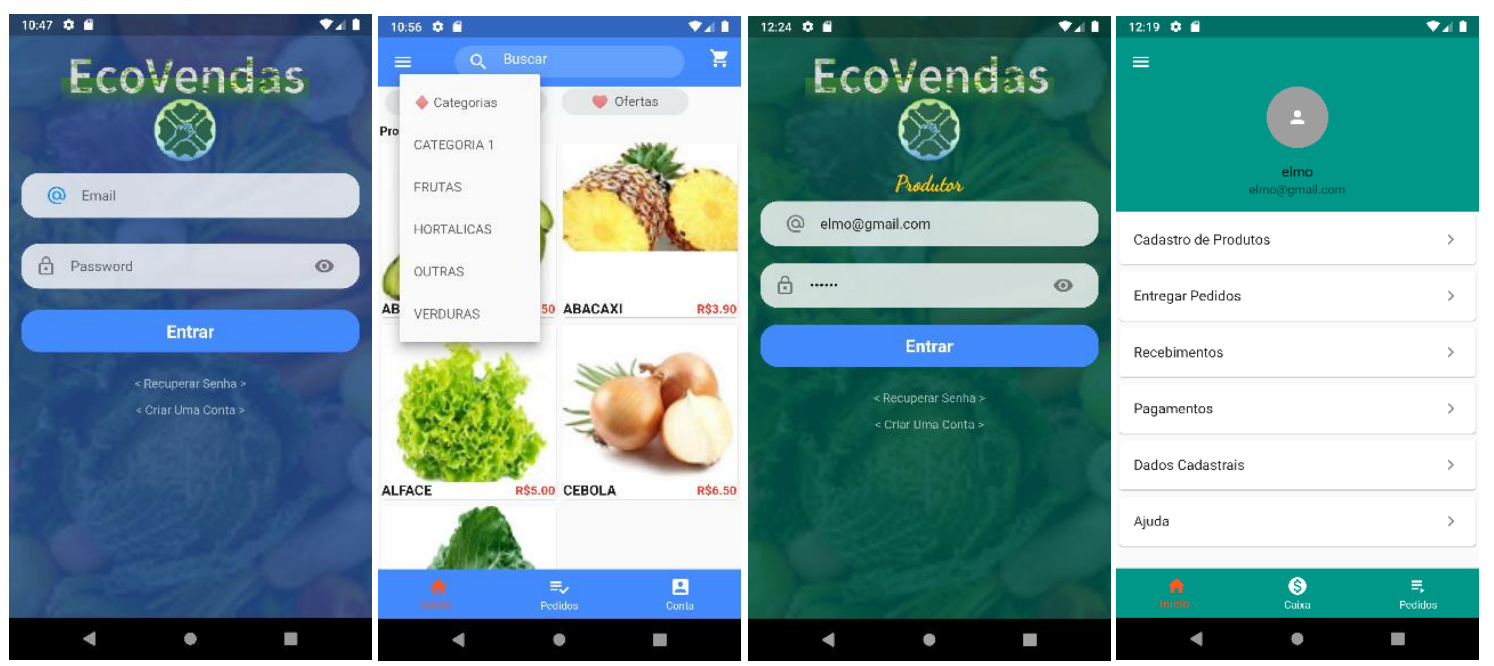

Figura 4 - Telas do aplicativo do cliente e produtor do sistema Android.

Um destes pontos de entrega de produtos é na própria UFMT, chamada de Ecofeira, que ocorre as sextas-feiras, no período noturno. As telas em azuis apresentadas na figura 4, representam o sistema de compras sob a visão do cliente, na sequência temos a tela de Login, o carrinho de compras, os detalhes dos produtos na escolha dos itens, a tela com o menu de itens a venda, as opções do cliente e a tela de pagamento. As duas últimas telas em verde, representam o aplicativo do cliente e suas funcionalidades. Ao todo o APP possui aproximadamente 35 telas para os dois aplicativos. Todas as informações ficam armazenadas na base de dados do PostgreSQL, em um sistema de servidores virtualizados, no Instituto de Computação da UFMT. Também foi gerada uma 
versão para o sistema IOS da Apple, como apresentado no simulador do Iphone X na figura 5 .

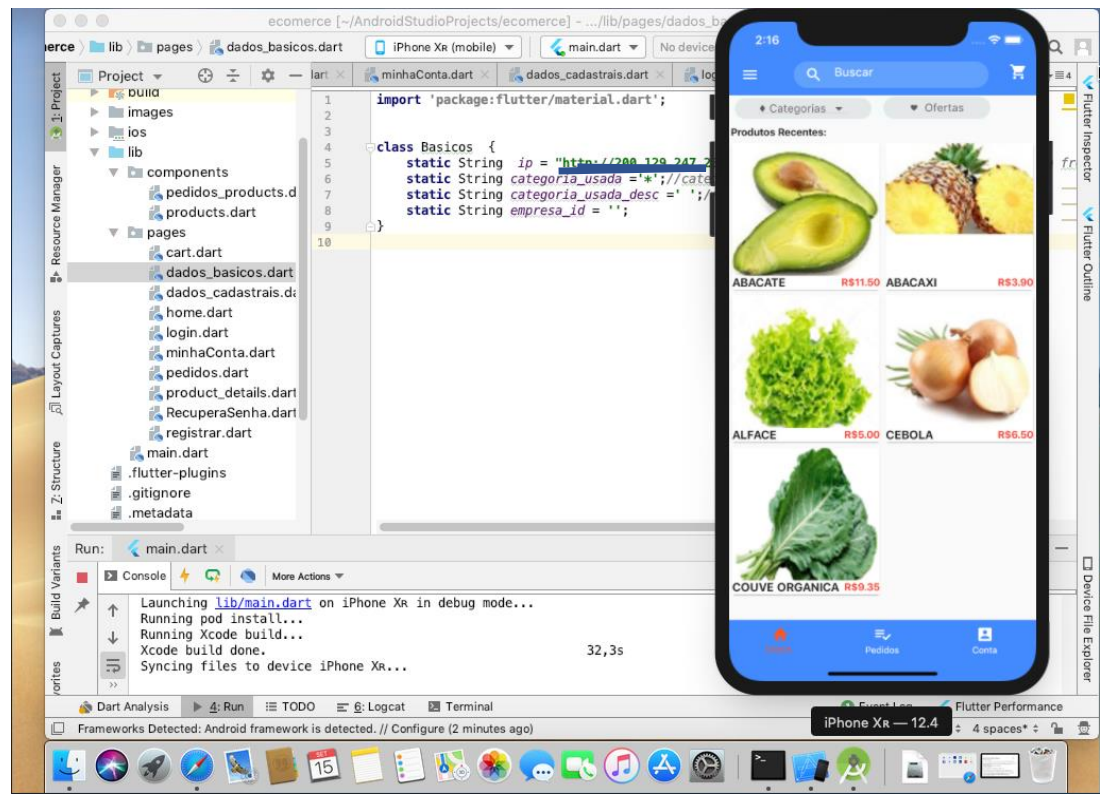

Figura 5 - Tela do App para a plataforma IOS da Apple.

\section{Conclusões}

O aplicativo encontra- se em fase de desenvolvimento e ainda não está disponível para a comercialização dos produtos, no entanto, já foi possível fazer uma experimentação via dispositivo Android e IOS. A previsão é que o APP atenda 80 produtores e cerca de 500 clientes. A criação desse APP, juntamente com as outras ações que compõe o Programa RECOPSOOL, possibilitam avanços importantes para o estabelecimento de relações de confiança entre entidades governamentais, empresariais, acadêmicas e empreendimento econômicos solidários, constituídos por membros de povos e comunidades tradicionais na área rural e urbana da baixada cuiabana. Nesse sentido, objetivo principal desse projeto, que é desenvolver um meio facilitador de comercialização entre os agricultores e o consumidor final, baseado em um APP, onde os estoques devem ser observados e reservas de compras possível pelos interessados, está sendo atingido. Está sendo desenvolvido, juntamente com os aplicativos, um sistema de sugestão de lista de compras utilizando Inteligência Artificial, baseado no histórico de compra dos clientes.

\section{Referências}

Brasil. (2010) "Plano Territorial de Desenvolvimento Rural Sustentável". Ministério do Desenvolvimento Agrário, Mato Grosso.

Gress, J. (2014) "Visual Effects and Compositing”. [S.1.]: New Riders. 23 páginas.

Dufresne, T. and Martin, J. (2003) "Process Modeling for E-Business". INFS 770 Methods for Information Systems Engineering: Knowledge Management and EBusiness. Spring.

O. Z. et al. (2014) "Incubadora Tecnológica de Cooperativas Populares da Universidade Federal de Mato Grosso - ITCP-UFMT”. Brasilia, DF: ABIPTI - Associação Brasileira das Instituições de Pesquisa Tecnológica. p. 372-381. 